\title{
Selective targeting of human colon cancer stem-like cells by the mTOR inhibitor Torin-1
}

\author{
Maria Giovanna Francipane ${ }^{1,2}$ and Eric Lagasse ${ }^{1}$ \\ ${ }^{1}$ McGowan Institute for Regenerative Medicine, Department of Pathology, University of Pittsburgh School of Medicine, \\ Pittsburgh, PA, USA. \\ ${ }^{2}$ RiMed Foundation, Palermo, Italy. \\ Correspondence to: Eric Lagasse, email: Lagasse@pitt.edu
}

Keywords: colorectal cancer; cancer stem cells; mTOR; apoptosis.

Received: August 21, $2013 \quad$ Accepted: September 17, $2013 \quad$ Published: September 19, 2013

This is an open-access article distributed under the terms of the Creative Commons Attribution License, which permits unrestricted use, distribution, and reproduction in any medium, provided the original author and source are credited.

\section{ABSTRACT:}

Metastatic colorectal cancer (CRC) is incurable for most patients. Since mammalian target of rapamycin (MTOR) has been suggested as a crucial modulator of tumor biology, we aimed at evaluating the effectiveness of $m$ TOR targeting for CRC therapy. To this purpose, we analyzed mTOR expression and the effect of mTOR inhibition in cancer stem-like cells isolated from three human metastatic CRCs (CoCSCs).

CoCSCs exhibited a strong mTOR complex 2 (mTORC2) expression, and a rare expression of mTOR complex 1 (mTORC1). This latter correlated with differentiation, being expressed in CoCSC-derived xenografts. We indicate Serum/glucocorticoidregulated kinase 1 (SGK1) as the possible main mTORC2 effector in CoCSCs, as highlighted by the negative effect on cancer properties following its knockdown. mTOR inhibitors affected CoCSCs differently, resulting in proliferation, autophagy as well as apoptosis induction. The apoptosis-inducing mTOR inhibitor Torin-1 hindered growth, motility, invasion, and survival of CoCSCs in vitro, and suppressed tumor growth in vivo with a concomitant reduction in vessel formation. Torin-1 also affected the expression of markers for cell proliferation, angio-/lympho-genesis, and stemness in vivo, including Ki67, DLL1, DLL4, Notch, Lgr5, and CD44. Importantly, Torin-1 did not affect the survival of normal colon stem cells in vivo, suggesting its selectivity towards cancer cells. Thus, we propose Torin-1 as a powerful drug candidate for metastatic CRC therapy.

\section{INTRODUCTION}

Colorectal cancer (CRC) is the second leading cause of cancer death in the United States [1]. Despite new treatment options developed in the last decade, the prognosis for patients with advanced or recurrent CRC remains poor.

The serine/threonine kinase mammalian target of rapamycin (mTOR) has been suggested as a crucial modulator of tumor cell growth and proliferation, and therefore a potential target for anticancer therapy [2]. Unfortunately, drug development against mTOR started when knowledge of its function was very preliminary, resulting in contradictory data and unsuccessful clinical trials. Several breakthroughs have recently changed the course of mTOR-oriented drug discovery. First, the fact that mTOR exists in two distinct complexes: mTORC1 containing Raptor, and mTORC2 containing Rictor [3]. Second, the discovery that Rapamycin (the first mTOR inhibitor identified) exerts an incomplete inhibition of mTORC1 and is inactive against mTORC2 under shortterm conditions [4]. Third, the existence of negative feedback loops linking mTOR to other pathways. Akt can phosphorylate mTOR in mTORC1, consequently leading to phosphorylation of ribosomal $\mathrm{S} 6$ protein kinase 1 (S6K1) and eIF4E-binding protein 1 (4E-BP1), mediators of protein translation and cell growth [5]. mTORC1activated S6K1 phosphorylates Rictor and/or Insulin receptor substrate (IRS)-1, thus inhibiting mTORC2 and phosphatidyl inositol 3-kinase (PI3K)/Akt signaling, 
respectively [6,7]. More recent findings indicate that mTORC1 also phosphorylates Growth Factor Receptor Bound Protein 10 (Grb10), leading to accumulation of Grb10 and negative feedback inhibition of PI3K and Microtubule-associated protein kinase/Extracellularsignal regulated kinase (MAPK/ERK) pathway [8]. mTORC2 plays an important role in cell survival, metabolism, proliferation and cytoskeleton organization, as it phosphorylates Protein Kinase $\mathrm{C} \alpha(\mathrm{PKC} \alpha)$, SGK1, as well as Akt, allowing for its complete activation [3, 9-11]. Documented pro-survival rather than anticancer effects of Rapamycin likely resulted from disruption of the mTORC1-dependent negative feedback loop to mTORC2 and IRS-1/PI3K. This awareness pushed for development of a new generation of inhibitors, which compete with ATP in the catalytic site of mTOR, and inhibit both complexes [12]. Unfortunately, the effects of the so-called mTOR kinase inhibitors (mTorKIs) have been poorly investigated.

Studies in $A p c \Delta 716$ mice, a mouse model of familial adenomatous polyposis, sustained the basis of MTORC1targeted drug development for therapy and prevention of colon polyps and cancers $[13,14]$. However, blocking a specific pathway may disrupt the balance between signaling pathways and enhance oncogenic signals. In that regard, in parallel with its cytostatic effect, Rapamycin strongly increased MAPK kinase (MEK)/ERK activity, resulting in the appearance of a spindle morphology and higher invasiveness of K-Ras-transformed intestinal epithelial cells (IECs) [15]. This indicated the need for new drugs able to overcome the relief of feedback inhibition of pro-survival, pro-invasive and pro-metastatic pathways. Besides mTORC1, mTORC2 is overexpressed in CRC and plays an important role in cancer biology [16]. Recent studies have demonstrated the efficacy of the dual kinase inhibitors NVP-BEZ235 and pp242 in CRC cell linederived xenografts $[17,18]$. Nevertheless, a remarkable intrinsic resistance of a large proportion of CRC cell lines to mTorKIs, including the above-mentioned compounds, was also described, warranting further studies [19].

With the formulation of the cancer stem cell (CSC) hypothesis in tumors including $\mathrm{CRC}$, it has become clear that successful tumor eradication requires the depletion of a population of precursor/progenitor cells with indefinite self-renewal capacity, chemotherapy resistance, and metastatic ability $[20,21]$. Despite this, to our knowledge, only one study investigated the effects of mTOR inhibitors in cancer stem-like cells so far. mTOR signaling was shown to be activated in colorectal cell linederived spheres in serum-free medium [22]. Treatment with Rapamycin and pp242 diminished sphere-forming capacity as well as ALDH1 activity. However, only pp242 suppressed the enrichment of $\mathrm{ALDH}^{+}$cells induced by chemotherapy, thus highlighting an essential role of the mTORC2 signaling in the maintenance of the CRC stemlike phenotype. Although this study further confirmed the importance of mTOR signaling in CRC, the authors did not perform sufficient functional experiments to assess the effect of mTOR inhibition on biological properties and tumorigenic potentials of CRC stem-like cells. Moreover, the existence of a controversy in the literature as to whether $\mathrm{ALDH}^{+}$cells isolated from cancer cell lines can serve as in vitro model for CSC study, further indicates the need to study the effect of mTOR inhibition using alternative methods to identify and characterize CSCs. Multiple cell-surface proteins have been proposed as potential candidate markers for colon stem-like cells (CoCSCs), and our in vitro system efficiently enriches for these cells [23]. Here, we first analyzed CoCSCs for expression of major mTORC $1 / 2$ pathway components. We then tested different mTOR inhibitors, either alone or in combination with standard chemotherapy. Through these studies, we identified Torin- 1 as the most powerful inhibitor among those examined for CRC therapy.

\section{RESULTS}

\section{mTORC2 likely regulates physiology of both colon cancer progenitor and mature cells, while mTORC1 likely contributes to CoCSC differentiation.}

Although several mTOR pathway components have been investigated in a number of cancers including those of the colon [24], to our knowledge, no study investigating their expression in patient-derived CoCSCs has been reported so far. By immunofluorescence, we therefore analyzed the expression of Akt Ser473, mTOR Ser2448, mTOR Ser2481, SGK1 Ser422, and PKCa Ser657, in CoCSCs derived from three human metastatic CRCs (Tu12, Tu21, and Tu22 cells) [23]. Since these cells were grown on a rodent feeder layer, co-staining with an anti-HLA antibody was necessary to discriminate human (CRC) versus non-human (stroma) cells. Comparable results were obtained in all three cell lines tested. CoCSCs exhibited unexpectedly low Akt signaling but mTORC2 activation, as revealed by strong phosphorylation in all the cells of mTOR at Ser2481 and of its effectors SGK1 and PKC $\alpha$, at residues previously reported to be modified following mTORC2 activation (Figure 1A) [2]. A rare positivity for mTOR Ser2448 (indicative of mTORC1 activation status [2]) and infrequency of Thr389 phosphorylation of the p70S6K1 mTORC1 effector (data not shown) were also observed, indicating that as compared to mTORC1, mTORC2 might play a much more important role in regulating CoCSC physiology. Moreover, mTOR Ser2481 and Rictor co-localized, further indicating mTORC2 activation in our system. Interestingly, mTOR Ser2481 co-localized with $\gamma$-tubulin in centrosomes, thus suggesting a potential role for $\mathrm{mTORC} 2$ in the control of CoCSC proliferation (Figure 1B). While mTOR 
Ser2448 and p70S6K1 Thr389 were barely detectable in vitro, they were clearly expressed in vivo, together with mTOR Ser2481 and SGK1 Ser422 (Figure 1C). Because CoCSC differentiation has been previously observed after transplantation in immunodeficient mice [23], our immunostaining suggests a possible regulatory role of mTORC1 in CoCSC differentiation and of mTORC 2 in the physiology of both stem/progenitor and mature tumor cells.

\section{SGK1 facilitates CoCSC growth and drug resistance.}

The finding that CoCSCs expressed low levels of activated Akt might be explained in light of the recent observation that activated Akt in CRC correlates with low stage and good prognosis, [25] and this was not our case, since we were analyzing cells isolated from CRC metastases to the liver [23]. The fact that despite low Akt activation, CoCSCs showed mTORC2 activation, led us to hypothesize that Akt could not have been a major mTORC2 effector in our system. SGK1 is the main mTORC2 effector in yeast and worms [26]; thus, we hypothesized that this could also have been the case with CoCSCs. To prove this hypothesis, we investigated whether SGK1 knockdown could affect cancer properties. Tu12, Tu21 and Tu22 cells were purified from contaminating feeder cells, grown on plastic, and infected with copGFP control, control shRNA or SGK1 shRNA lentiviral particles (Figure 2A). RT-PCR analysis revealed a significant decrease in SGK1 mRNA levels $72 \mathrm{~h}$ after transfection (Figure 2B, left), while immunofluorescence analysis highlighted a strong decrease of SGK1 phosphorylation following puromycin selection (Figure 2B, right). Decreased clonogenicity (Figure 2C), invasive ability ( $\mathrm{p}=0.0006)$ (Figure 2D), and a 2-5fold increased Oxaliplatin-induced apoptosis (Figure 2E-F), were also observed following SGK1 knockdown. Thus, rather than Akt, SGK1 could be the main mTORC2 effector in CoCSCs.

\section{mTOR inhibitors differently affect CoCSC viability.}

Since mTORC2 activation characterized CoCSCs in vitro, we compared the effects of various mTorKIs
A
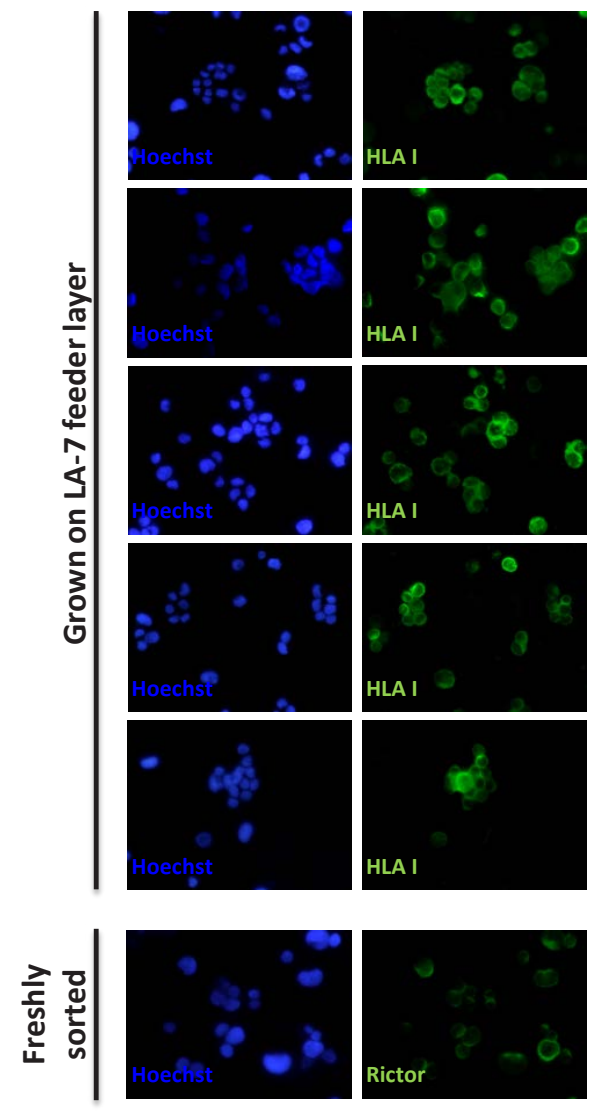
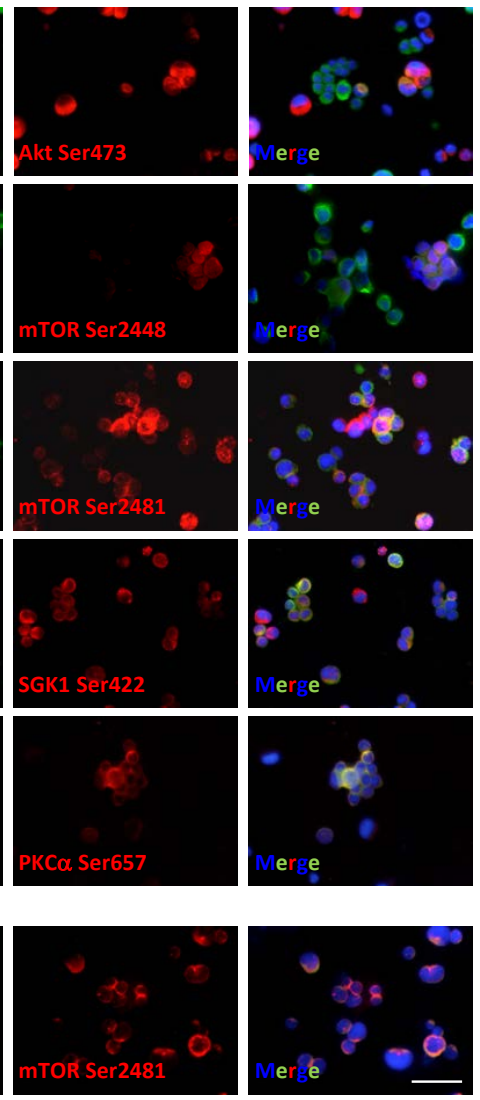

B

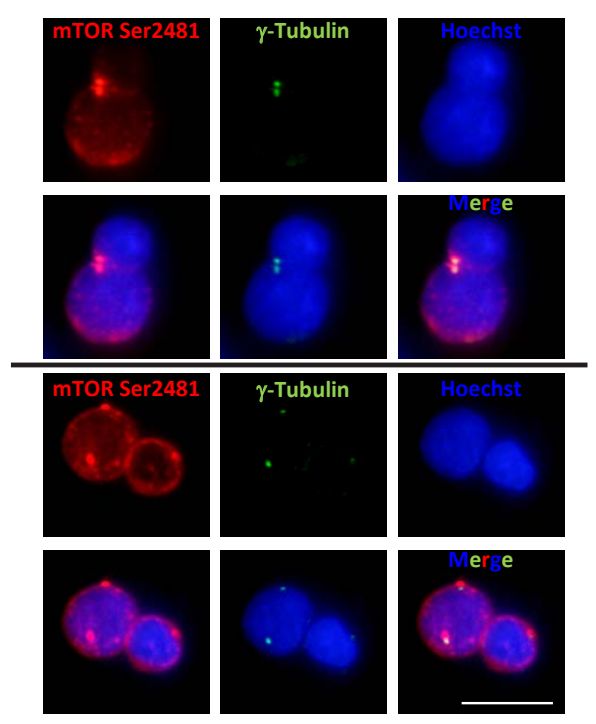

C
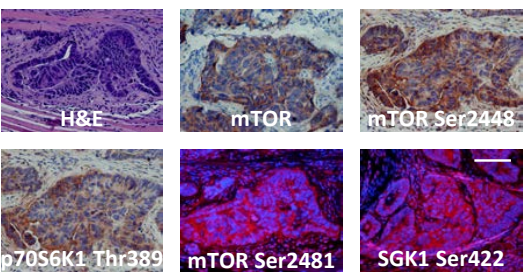

Figure 1: Expression of mTORC1/2 pathway components in CoCSC-derived cultures and xenografts. Immunofluorescence pictures of Tu22 showing (A) expression of distinct mTOR pathway components, and (B) co-localization of mTOR Ser2481 and $\gamma$-tubulin. Scale bars, $100 \mu \mathrm{m}$. (C) Hematoxylin and eosin (H\&E), immunohistochemistry (AEC, red color) or immunofluorescence staining for different mTOR pathway components on PFA-fixed, paraffin-embedded serial sections of Tu12-derived xenografts. Scale bar, $100 \mu \mathrm{m}$. 
(Ku-0063794, WYE-354, pp242, and Torin-1) to first-generation mTOR inhibitors (Rapamycin and Temsirolimus) on the three CoCSC lines previously examined. Feeder cell-depleted CoCSCs were treated with vehicle or a serial dilution $(0.001-10 \mu \mathrm{M})$ of the above-mentioned compounds for $72 \mathrm{~h}$. Even high drug concentrations were often not sufficient to affect cell viability (Figure 3A, left). Interestingly, mTOR inhibitors sometimes induced cell proliferation. Only Torin-1 decreased cell viability in a dose-dependent fashion.
$1 \mu \mathrm{M}$ decreased $\mathrm{Tu} 12, \mathrm{Tu} 21$, and $\mathrm{Tu} 22$ cell viability to $65 \% \pm 2.3,60 \% \pm 5.2$, and $51 \% \pm 4.3 \%$, respectively, while $10 \mu \mathrm{M}$ killed all of the cells. $10 \mu \mathrm{M}$ pp242 caused the accumulation of large cytoplasmic vacuoles inside the cells (Figure 3A, right). Additional studies revealed that pp242 induced autophagy, as indicated by acidic vesicular organelle (AVO) formation, changes in the localization of the autophagosome marker LC3 from diffuse cytosolic to a punctate distribution (Supplementary Figure 1A), and increased Beclin-1 mRNA levels
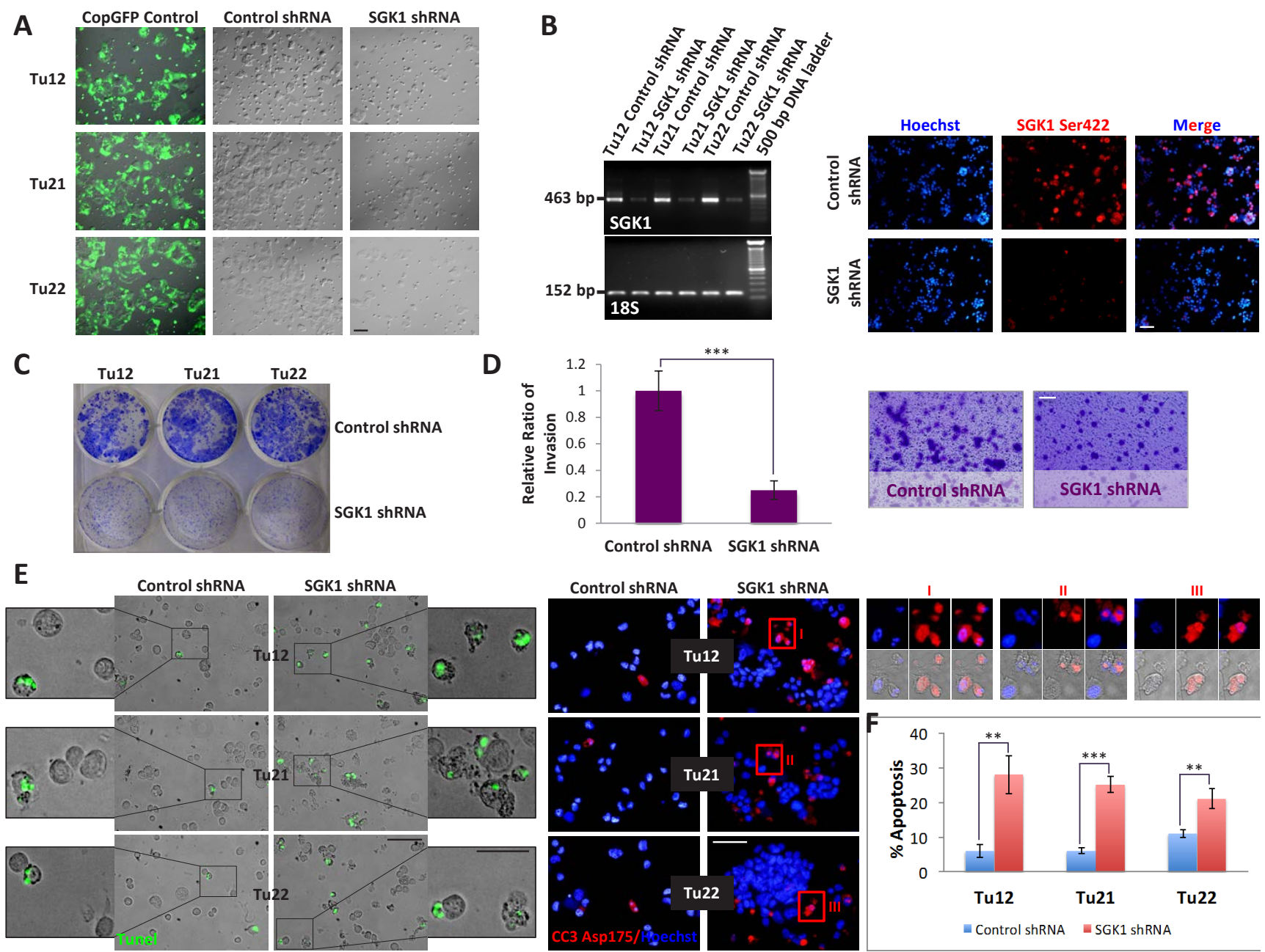

Figure 2: SGK1 knockdown reduces CoCSC growth, invasive ability and chemoresistance. Tu12, Tu21 and Tu22 were infected with copGFP control, control shRNA or SGK1 shRNA lentiviral particles (MOI=6.5). 72h post-transfection, cells were subjected to (A) light microscopy, and (B, left) RT-PCR analysis for SGK1 or 18S housekeeping gene as internal control. Scale bars, 100 $\mu \mathrm{m}$. After additional 5 days of puromycin selection $(1.5-2 \mu \mathrm{g} / \mathrm{mL})$, cells were analyzed by immunofluorescence for SGK1 Ser422 (B, right). Scale bar, $100 \mu \mathrm{m}$. (C) Decreased CoCSC clonogenicity following SGK1 knockdown. One hundred thousand cells infected with control or SGK1 shRNA lentiviral particles were plated in each well of a 6 -well plate. 2 weeks later, colonies were fixed and stained with $0.2 \%$ crystal violet (CV) in 10\% ethanol. (D) Bar graph (left) and optical imaging (right) of CV-stained transwells showing reduced invasive potential of SGK1-silenced Tu12 cells. Scale bar, $100 \mu \mathrm{m}$. Fifteen thousand cells infected as in (C) were seeded on growth factor reduced Matrigel (2mg/ $\mathrm{ml}$ )-coated transwells and allowed to invade for $48 \mathrm{~h}$. Data are presented as relative ratio of invasion from one experiment representative of two independent experiments carried out in triplicate $(* * * p<0.001)$ (the regions representing invaded cells were selected using the "Magic Wand" tool, and the highlighted pixels counted using the histogram command in Adobe Photoshop). (E) Merged fluorescent TUNEL assay and optical imaging (left; scale bars, 100 or $50 \mu \mathrm{m}$ ), and cleaved caspase-3 (CC3) Asp175 immunofluorescence (right, scale bar, 100 $\mu \mathrm{m})$ of Tu12, Tu21 and Tu22 cells infected as in (C) following $1 \mu \mathrm{M}$ Oxaliplatin treatment for $48 \mathrm{~h}$. Enlarged images (I, II, III) show CC3 reactivity in apoptotic bodies. $(\mathrm{F})$ Bar graph showing mean percentage $( \pm \mathrm{SD})$ of apoptotic cells calculated considering three different microscopic fields of TUNEL assay and CC3 staining $(* * p<0.01, * * * p<0.001)$. 
(Supplementary Figure 1B). A late-stage inhibitor of autophagolysosome formation, Bafilomycin A1, effectively blocked the accumulation of pp242-induced AVOs, but did not further sensitize cells to the effects of mTOR inhibition (Supplementary Figure 1C). In contrast, autophagy inhibition alleviated pp242 cytostatic effects, as proliferative rates of treated cells returned to basal levels (data not shown). Moreover, a transient and weak $\mathrm{S}$ phase cell cycle arrest accompanied pp242-induced autophagy (Supplementary Figure 1D), further indicating that autophagy was not delaying apoptotic cell death, but effectively rescuing cells from death.

As expected, both Rapamycin and Temsirolimus did not affect mTOR Ser2481 phosphorylation (Supplementary Figure 2A) and low Rapamycin doses $(10 \mathrm{nM})$ induced Akt feedback activation (Supplementary Figure 2B). p70S6K1 Thr389 levels were very low in CoCSCs and not altered by Rapamycin exposure up to $1 \mu \mathrm{M}$. Conversely, Rapamycin markedly decreased Grb10 protein abundance (Supplementary Figure 2C), suggesting that the relief of Grb10-mediated negative feedback inhibition of PI3K may have sometimes induced CoCSCs to activate Akt and proliferate.

We then aimed at testing mTOR inhibitors in combination with standard chemotherapy. Tu12, Tu21 and Tu22 cells were treated with $5 \mu \mathrm{M}$ Oxaliplatin or $100 \mu \mathrm{M} 5$-Fluorouracil alone or in combination with $10 \mu \mathrm{M}$ Rapamycin, Temsirolimus or WYE-354 for $72 \mathrm{~h}$. The mTOR inhibitors tested did not show additive or synergistic effects in combination with chemotherapeutics (Figure 3B). Rather, Temsirolimus rescued Oxaliplatintreated Tu22 cells $(\mathrm{p}=0.0075)$, while WYE-354 rescued Oxaliplatin-treated Tu12 $(\mathrm{p}=0.04)$ and Tu22 cells $(\mathrm{p}=0.008)$, as well as 5-Fluorouracil-treated Tu12 cells $(\mathrm{p}=0.03)$. Thus, mTOR inhibitors may have a beneficial role by protecting cells against pro-apoptotic insults. There was no observed benefit of combining Ku-0063794, Torin-1 or pp242 with chemotherapeutics (data not

A
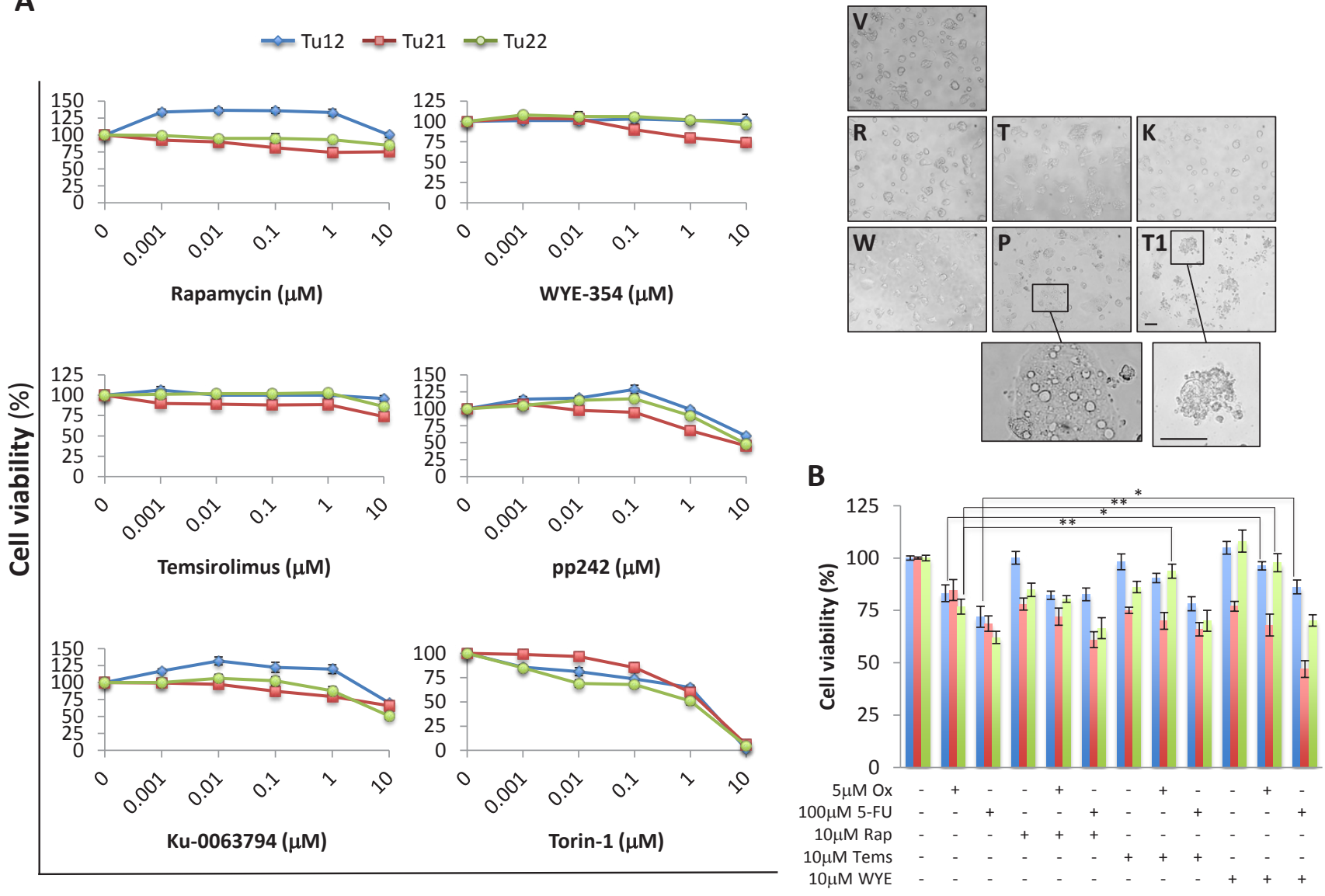

Figure 3: Differential effects of mTOR inhibitors on CoCSC viability. (A) Line graphs (left) and optical imaging (right)

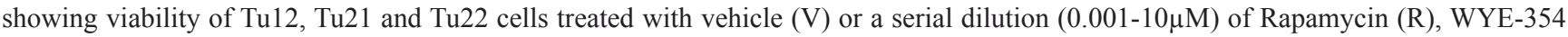
(W), Temsirolimus (T), pp242 (P), Ku-0063794 (K) or Torin-1 (T1). Scale bars, 200 $\mu$ m. The number of viable cells was measured by MTS assay after $72 \mathrm{~h}$ of drug exposure. Data are expressed as mean percentage $( \pm \mathrm{SD})$ of viable cells as compared to respective control cultures, obtained from triplicate absorbance readings from at least three independent experiments. Optical images were taken from Tu22 cells exposed to $10 \mu \mathrm{M}$ of each drug for $72 \mathrm{~h}$. (B) Bar graph showing mean percentage ( $\pm \mathrm{SD}$ ) of viable cells following treatment with Oxaliplatin

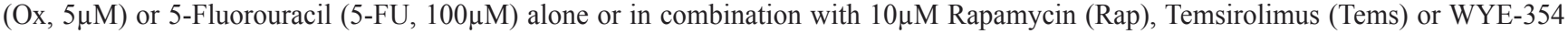
(WYE) for $72 \mathrm{~h}$. The number of viable cells was obtained as in (A) $\left(* \mathrm{p}<0.05,{ }^{* *} p<0.01\right)$. 
shown). Taken together, Torin-1 as a single agent, is the most powerful inhibitor among those examined for CRC therapy, as it efficiently suppresses tumor growth in vitro.

\section{Torin-1 triggers CoCSC apoptosis.}

Various techniques were used to determine whether Torin-1 induced apoptosis. $5 \mu \mathrm{M}$ Torin-1 treatment for 15h suppressed mTOR Ser2481 phosphorylation (Figure 4A) and induced apoptosis, as indicated by caspase-3 activation, monitored by both immunofluorescence and flow cytometry analysis (Figure 4B), and appearance of TUNEL-positive half moon shaped and fragmented nuclei
(Figure 4C). Following $72 \mathrm{~h}$ of treatment, all the cells were apoptotic (Figure 4D). Importantly, $5 \mu \mathrm{M}$ Torin-1 treatment for $15 \mathrm{~h}$ resulted in sub-G1 cell accumulation (Figure 4E), and appearance of single Annexin $\mathrm{V}^{+}$cells (Figure 4F), both indicative of apoptosis induction.

Emergence of resistant clones represents a main problem of current therapies. To understand whether CoCSCs could develop Torin-1 resistance, Torin-1 resistant Tu12, Tu21, and Tu22 cells were generated, as depicted in Supplementary Figure 3A. Cells could now survive $5 \mu \mathrm{M}$ Torin-1, but they were no longer able to extensively proliferate in vitro (Supplementary Figure 3B). S.c. injection of Torin-1 resistant cells into mice $(n=7)$ did not generate palpable tumors during a 7-wk observation
A

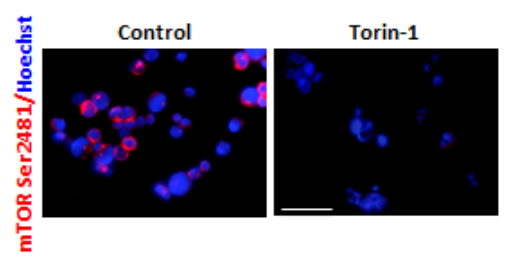

C

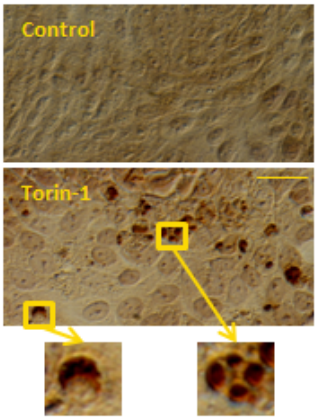

$\mathbf{E}$

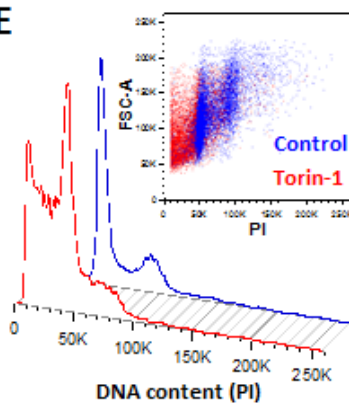

B

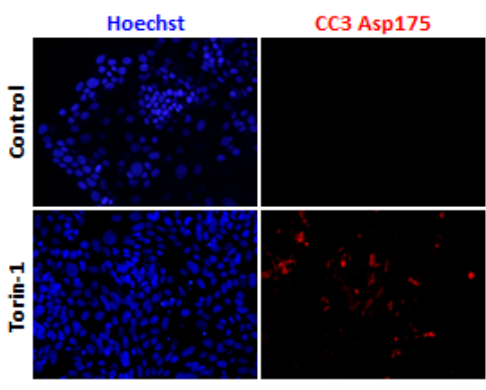

D

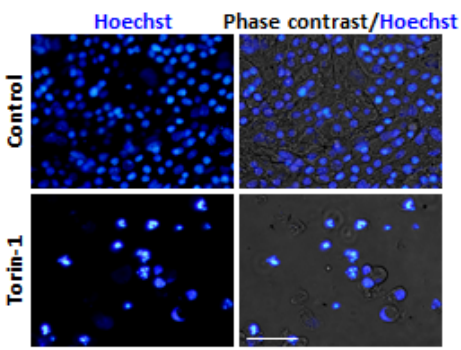

$\mathbf{F}$
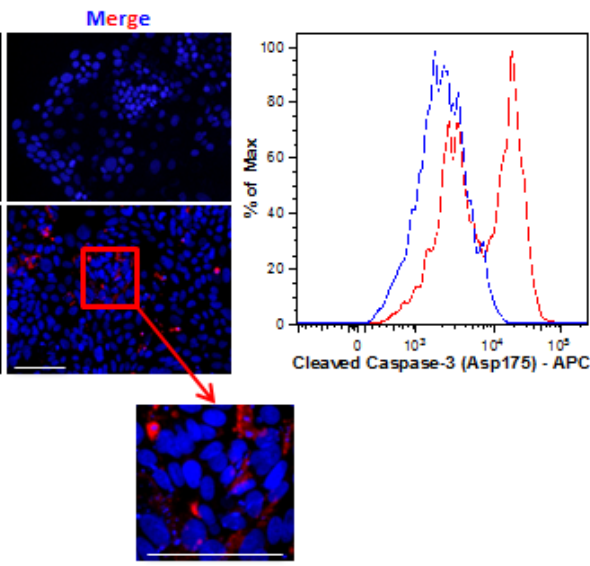

\begin{tabular}{|c|c|c|}
\hline Phase & Control & Torin-1 \\
\hline SubG1 & $3.48 \%$ & $48.1 \%$ \\
\hline G0/G1 & $57.6 \%$ & $34.4 \%$ \\
\hline S & $13.1 \%$ & $9.02 \%$ \\
\hline G2/M & $19.4 \%$ & $6.18 \%$ \\
\hline
\end{tabular}
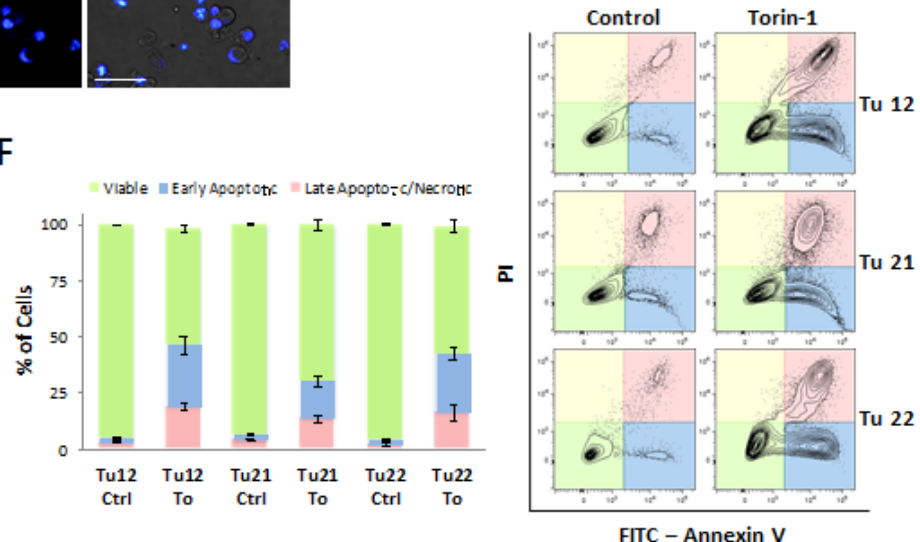

Figure 4: Torin-1 triggers CoCSC apoptosis. Immunofluorescence pictures of control or Torin-1-treated $(5 \mu \mathrm{M}, 15 \mathrm{~h}) \mathrm{Tu} 12$ cells

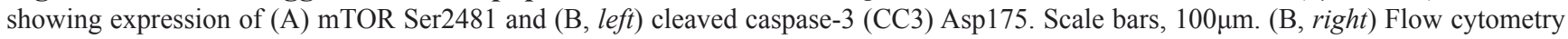
histogram showing CC3 Asp175 staining on PFA- and methanol-fixed Tu12 cells treated as in (A). (C) Optical imaging of TUNEL assay

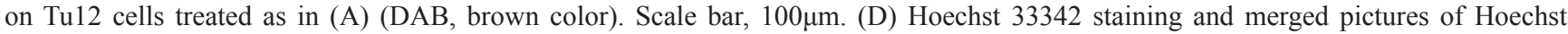
staining and optical imaging of Tu12 cells treated with $5 \mu \mathrm{M}$ Torin- 1 or vehicle as control for $72 \mathrm{~h}$. Scale bar, $100 \mu \mathrm{m}$. Condensed chromatin, fragmented nuclei, and apoptotic bodies can be observed following treatment. (E) DNA content histogram (left) and table (right) showing sub-G1 cell accumulation after Torin-1 treatment $(5 \mu \mathrm{M}, 15 \mathrm{~h})$. Tu12 cells were fixed with $70 \%$ ethanol, RNase treated $(0.2 \mathrm{mg} / \mathrm{ml})$, and stained with PI $(40 \mu \mathrm{g} / \mathrm{ml})$ before being analyzed with a flow cytometer. Quantitative analysis is based on the Dean-Jett-Fox curve-fitting model. (F, left) Stacked bar graph showing mean percentage ( $(\mathrm{SD})$ of viable, early apoptotic or late apoptotic/necrotic Tu12, Tu21 or Tu22 cells treated as in (A), determined using FITC Annexin V/PI staining. Results are representative of at least two experiments. (F, right) Flow cytometry contour plots of FITC Annexin V/PI-stained Tu12, Tu21 and Tu22 cells treated as in (A). 
period (Supplementary Figure 3C). Nevertheless, examination of skinned mice revealed two mice had formed very small tumors. Thus, CoCSC cultures that have been subjected to a prolonged, continuous, multistep selection with Torin-1 contain a strikingly reduced tumorinitiating cell population, thus encouraging Torin-1 potential use for CRC therapy.
Torin-1 hinders growth, motility, invasion, and survival of distinct CoCSC subpopulations.

Despite the first wave of enthusiasm surrounding the CSC field, no consensus has emerged so far about cell surface marker profiles that define CoCSCs, Initially

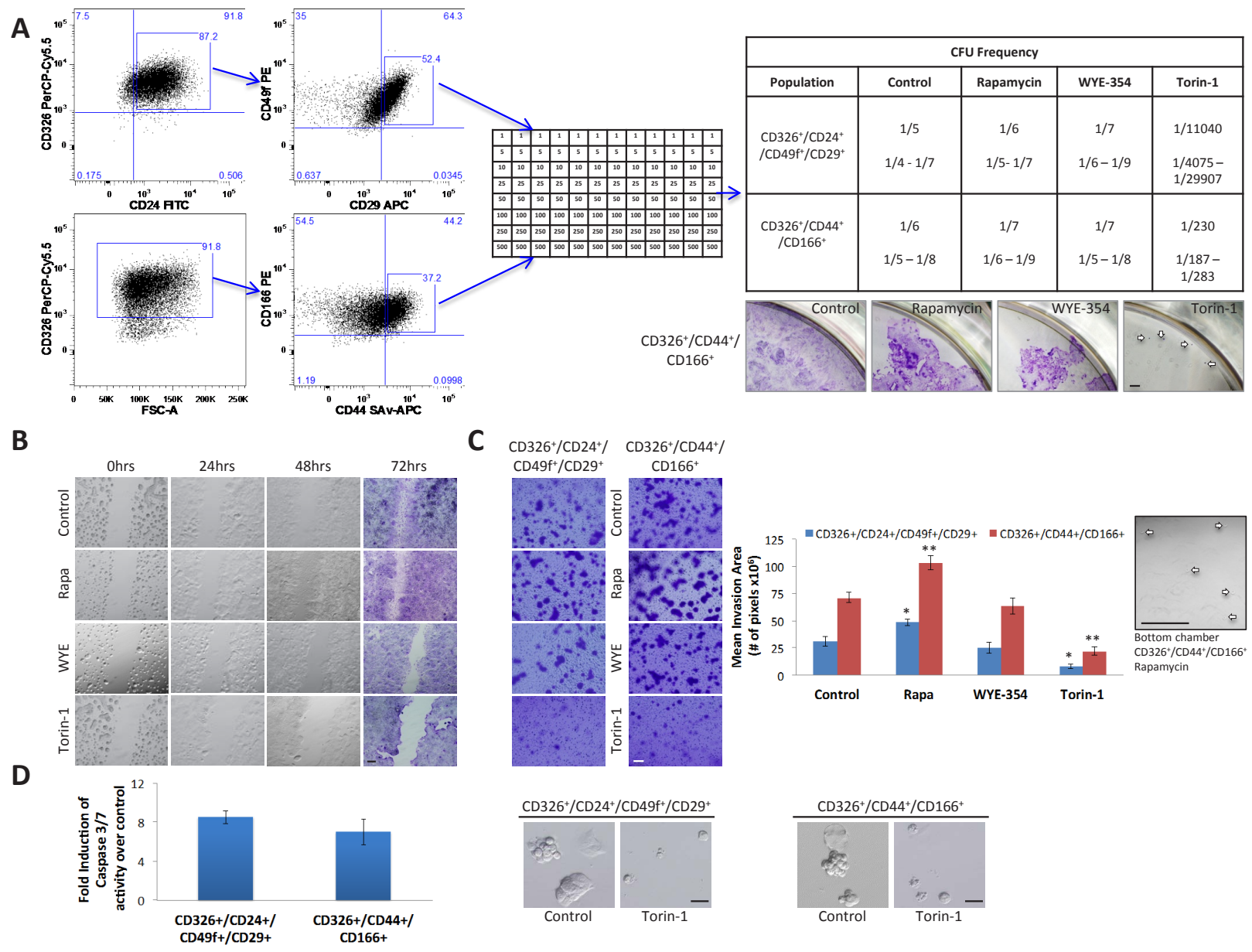

Figure 5: Rapamycin, WYE-354 and Torin-1 differently affect cancer properties of distinct CoCSC subpopulations. (A) Flow cytometry dot plots (left) showing gates used for sorting Tu12 cells. Cells were stained with CD326 PerCP-Cy5.5, CD24 FITC, CD49f PE, CD29 APC, and Sytox Blue or CD326 PerCP-Cy5.5, CD166 PE, CD44 SAv-APC, and Sytox Blue. CD326 $6^{+}$CD24 $/ C D 49 f^{+} /$ $\mathrm{CD} 29^{+}$and $\mathrm{CD} 326^{+} / \mathrm{CD} 44^{+} / \mathrm{CD} 166^{+}$subpopulations were sorted directly into 96 -well plates in medium containing vehicle, $1 \mu \mathrm{M}$ Rapamycin, WYE-354 or Torin-1 (see the table for cell densities, middle panel). Medium was replaced every $72 \mathrm{~h}$ up to 12 days, when wells containing colonies were scored and CFU frequencies $( \pm \mathrm{SE})$ estimated using the LCalc ${ }^{\mathrm{TM}}$ software (StemCell Technologies) (upper right panel). Optical imaging of CV-stained wells (lower right panel) showing confluence rates of $\mathrm{CD} 326^{+} / \mathrm{CD} 44^{+} / \mathrm{CD} 166^{+}$cells exposed to different

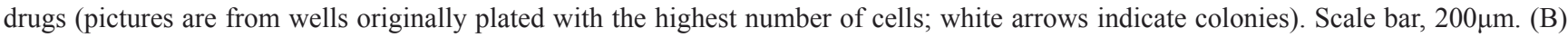
Optical imaging of unstained or CV-stained $\mathrm{CD} 326^{+} / \mathrm{CD}_{4} 4^{+} / \mathrm{CD} 166^{+}$cells treated as in (A) and migrating across the gap up to $72 \mathrm{~h}$. Scale bar, $200 \mu \mathrm{m}$. Thirty thousand cells were seeded into each well of a culture insert and grown overnight. After removal of the insert, a $500 \mu \mathrm{m}$ cell-free gap was created. Cells were therefore treated, and migration monitored at different time points. (C) Optical imaging of CVstained transwells (left) showing invasive potential of $\mathrm{CD} 326^{+} / \mathrm{CD} 24^{+} / \mathrm{CD} 49 \mathrm{f}^{+} / \mathrm{CD} 29^{+}$and $\mathrm{CD} 326^{+} / \mathrm{CD} 44^{+} / \mathrm{CD} 166^{+} \mathrm{Tu} 12$ cells treated as in (A). Scale bar, $100 \mu \mathrm{m}$. Fifteen thousand cells were sorted directly into growth factor reduced Matrigel $(2 \mathrm{mg} / \mathrm{ml})$-coated transwells and allowed to invade for $72 \mathrm{~h}$. Drugs were added to bottom chambers. Bar graph (middle) shows the mean ( $\pm \mathrm{SD}$ ) invasion area (pixels) from one representative experiment of two in triplicate, with similar results (statistical analysis was performed with respect to control samples; ${ }^{*} \mathrm{p}<0.05,{ }^{*} p<0.01$ ). Optical imaging (right) of a bottom chamber showing $\mathrm{CD} 326^{+} / \mathrm{CD} 44^{+} / \mathrm{CD} 166^{+}$cells crossing the porous membrane

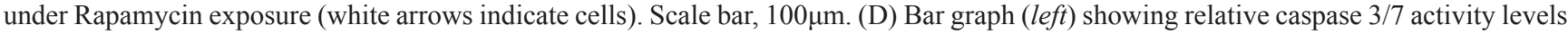
(fold increase over control) of CD $326^{+} / \mathrm{CD} 24^{+} / \mathrm{CD} 49 \mathrm{f}^{+} / \mathrm{CD} 29^{+}$and $\mathrm{CD} 326^{+} / \mathrm{CD} 44^{+} / \mathrm{CD} 166^{+}$Tu12 cells following treatment with vehicle or Torin-1 $(5 \mu \mathrm{M}, 15 \mathrm{~h})$, and optical imaging $(r i g h t)$ showing morphological changes in treated versus control cells. Scale bars, $200 \mu \mathrm{m}$. Data of caspase $3 / 7$ activities are presented as mean $( \pm \mathrm{SD})$ of the luminescence values obtained in triplicate determination from at least three independent experiments. 
described as a unique marker for immature intestinal cells, CD133 was later subject of huge controversy [27]. Conversely, the combined expression of CD $326^{\text {high }} / \mathrm{CD} 44^{+} /$ $\mathrm{CD}_{166^{+}}$was suggested as being more robust for CoCSC isolation [28]. Both CD $24^{+} / \mathrm{CD} 29^{+}$and $\mathrm{CD} 24^{+} / \mathrm{CD} 49 \mathrm{f}^{+}$ signature have been suggested to characterize putative mammary stem/progenitor cells [29]. Interestingly, we found colony-forming unit (CFU) frequencies of $\mathrm{CD} 326^{+} / \mathrm{CD}^{2} 4^{+} / \mathrm{CD} 49 \mathrm{f}^{+} / \mathrm{CD} 29^{+}$and $\mathrm{CD} 326^{+} / \mathrm{CD} 44^{+} /$ CD $166^{+}$CRC subpopulations to be very similar. For this reason, we chose these two subpopulations within Tu12 cells to further confirm Torin-1 anti-CoCSC activity. Particularly, we performed limiting dilution analysis, migration, and invasion assays, in the presence or absence of $1 \mu \mathrm{M}$ Rapamycin, WYE-354, or Torin-1. While CFU frequencies among Control, Rapamycin-, and WYE-354treated cells were similar, CFU frequencies following Torin-1 treatment were significantly decreased (Figure 5A, upper right panel). However, cells exposed to Rapamycin or WYE-354 were less confluent than control cells, and
Torin-1-treated cells generated very small colonies (Figure $5 \mathrm{~A}$, lower right panel). Compared to control cells, more cells migrated through the gap at $48 \mathrm{~h}$ and invaded the Matrigel layer at $72 \mathrm{~h}$ under Rapamycin exposure $(\mathrm{p}=0.035$ for $\mathrm{CD}_{2} 26^{+} / \mathrm{CD} 24^{+} / \mathrm{CD} 49 \mathrm{f}^{+} / \mathrm{CD} 29^{+}$, and 0.0056 for $\mathrm{CD}_{2} 26^{+} / \mathrm{CD}_{4} 4^{+} / \mathrm{CD} 166^{+}$cells) (Figure $5 \mathrm{~B}-\mathrm{C}$ ). Moreover, Rapamycin caused some cells to cross the porous membrane and adhere to the bottom chamber (Figure 5C, right). In contrast, control cell were completely unable to cross the membrane under experimental conditions. Although $72 \mathrm{~h}$ WYE-354 treatment did not affect Tu12 cell viability (Figure 3A, left), it slightly reduced migration, but not invasion of both subpopulations $(\mathrm{p}=0.37$ and $\mathrm{p}=0.36$, respectively) (Figure 5B-C). Conversely, Torin-1 strongly inhibited both migration and invasion of the selected subpopulations ( $\mathrm{p}=0.024$ and 0.009 , respectively), and activated apoptosis as evidenced by increased caspase 3/7 activity and morphological changes (Figure 5B-D), confirming its anti-CSC activity.
A

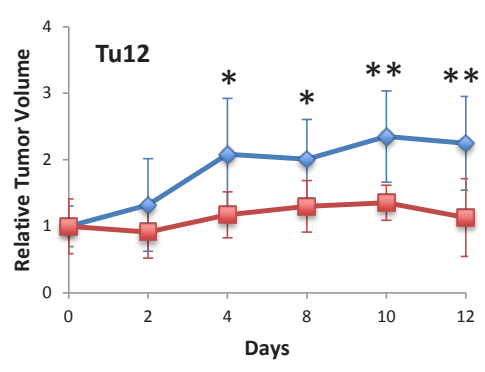

$\leadsto$ Control $\triangle$ Torin-1

C

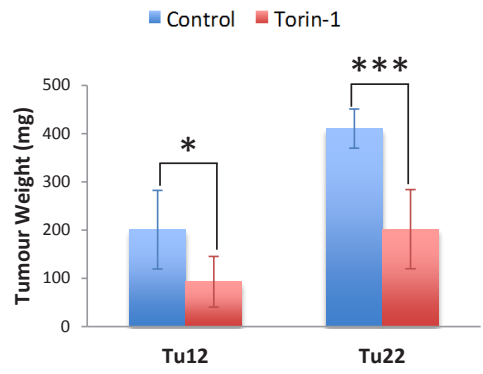

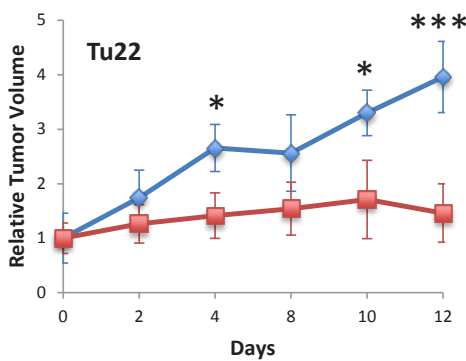

Days
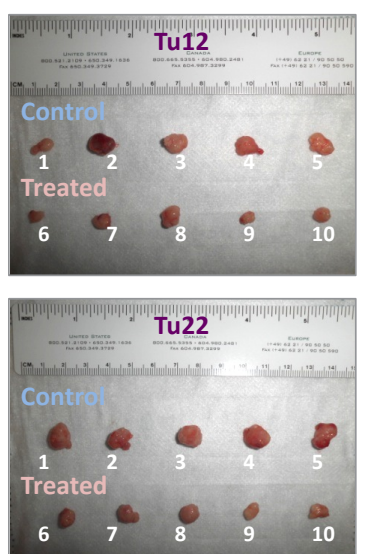

B

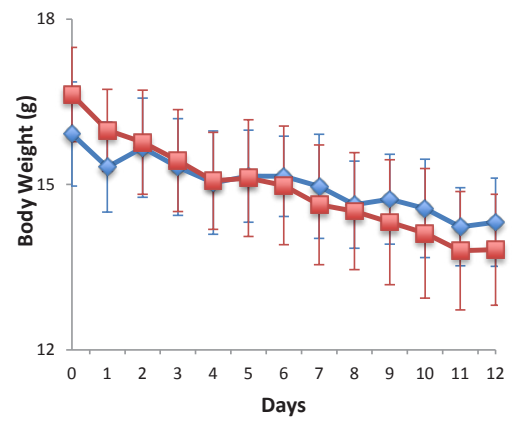

D

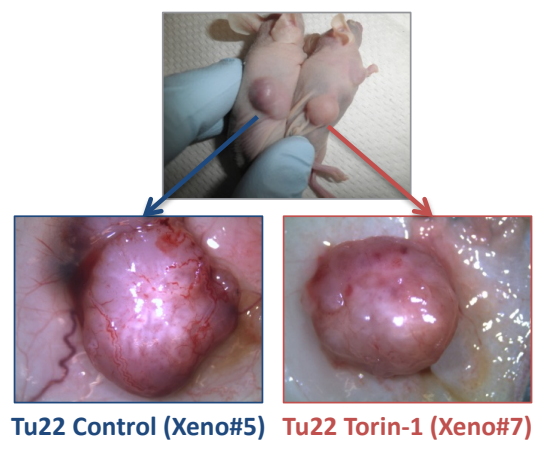

Figure 6: Torin-1 suppresses CRC growth and angiogenesis. (A) Line graphs showing relative Tu12 (left) or Tu22 (right) tumor volumes (ratios of tumor volumes to initial size at start of treatment) for control and treated mice as a function of time. $20 \mathrm{mg} / \mathrm{Kg}$ Torin- 1 , or vehicle was delivered by i.p. injection once daily for 12 days after the tumor reached the size of $150-250 \mathrm{~mm}^{3}$ (19 days after transplantation of $5 \mathrm{X} 10^{5}$ tumor cells/mouse; statistical analyses were performed with respect to control tumors; $\left.{ }^{*} \mathrm{p}<0.05,{ }^{*} * p<0.01,{ }^{* * *} p<0.001\right)$. (B) Line graph showing control and treated mouse body weight $(\mathrm{g})$ over a 12-day period. (C, left) Bar graph showing the weight (mg) of Tu12 and Tu22 xenografts excised from both control and treated groups $\left({ }^{*} \mathrm{p}<0.05,{ }^{* * *} p<0.001\right)$. (C, right) Macroscopic appearance of all xenografts excised. (D) Tu22 tumor-bearing mice after 12 days treatment with vehicle (upper picture, left mouse) or Torin-1 (upper picture, right mouse), and stereoscopic images of respective excised tumors (Xeno\#5 and Xeno\#7, lower pictures) showing different vascularization. 
Torin-1 reduces tumor growth and vessel formation in vivo.

To test whether Torin-1 could suppress CRC progression in vivo, we established Tu12 and Tu22 xenografts in nude mice. Then, mice received $20 \mathrm{mg} /$ $\mathrm{Kg}$ Torin-1 or vehicle every day up to 12 days. Torin-1treated tumors grew slower than control tumors (Figure 6A). Drug was well tolerated as no significant differences in body weight between the two groups were observed (Figure 6B). The mean weights of the excised tumors were approximately $50 \%$ less in mice treated with Torin- 1 with respect to control mice (Tu12, $\mathrm{p}=0.025$; $\mathrm{Tu} 22, \mathrm{p}=0.0009)$ (Figure 6C). Importantly, tumor vasculature was less developed in treated tumors (Figure 6D), suggesting Torin-1 anti-angiogenic activity.

Torin-1 decreases the expression of proliferative, angio-/lympho-genic, and stem cell markers, and activates apoptosis in vivo.

Different markers were evaluated by real-time qPCR analysis in both untreated and treated tumors (Figure 7A). With respect to control tumors, the proliferation
A

B

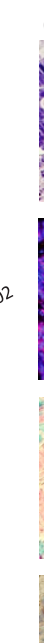

Tu22 (Xeno\#5 vs Xeno\#9)

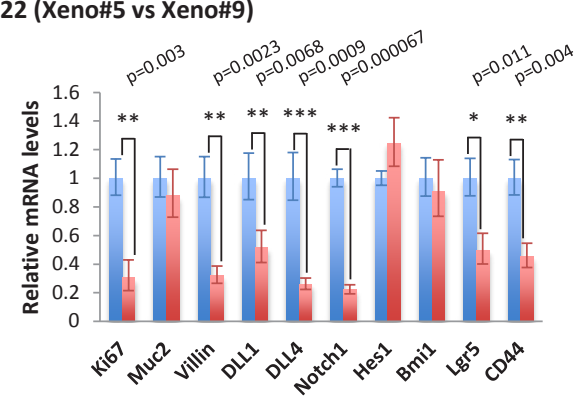

Tu12 (Xeno\#2 vs Xeno\#9)
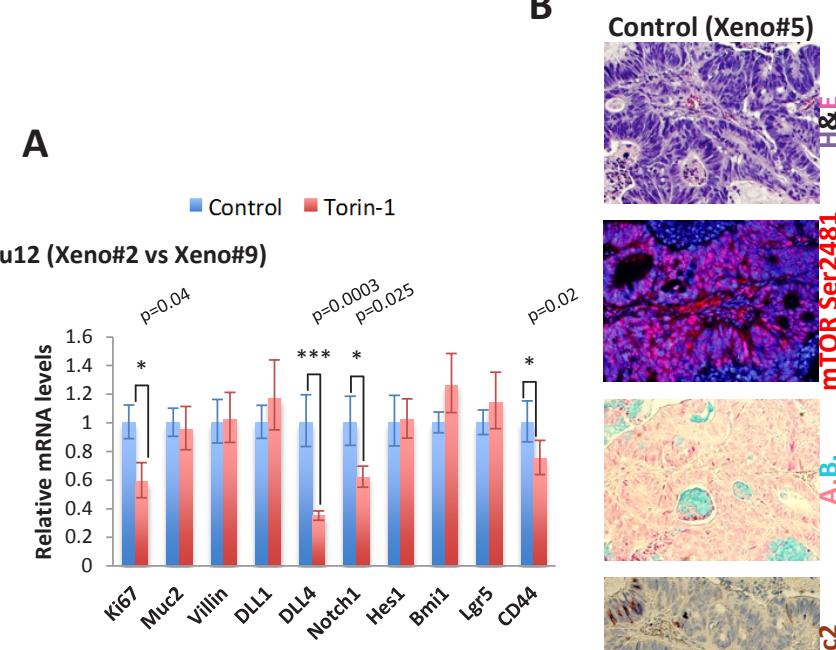

Torin-1 (Xeno\#7)
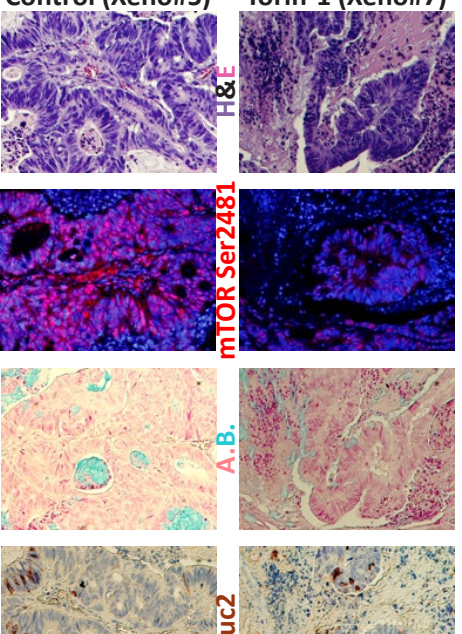

?
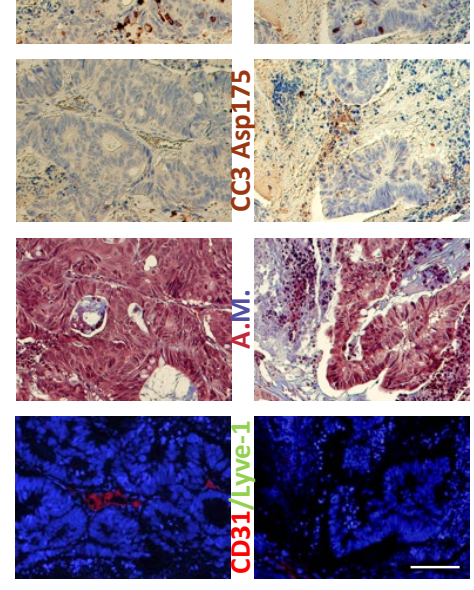

C

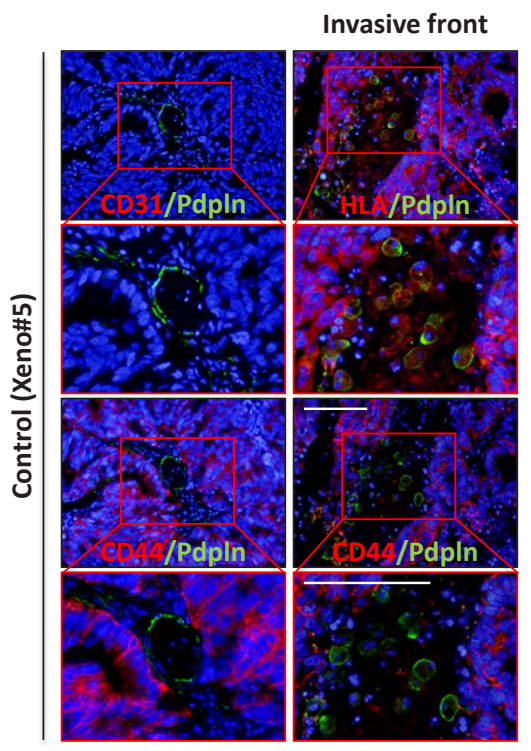

D
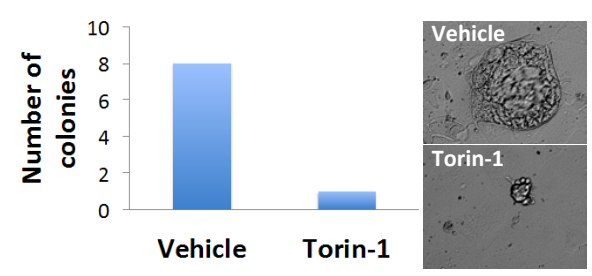

Figure 7: Torin-1 decreases the expression of proliferative, angio-/lympho-genic, and stem cell markers, and activates apoptosis in vivo. (A) Bar graphs showing relative real-time qPCR analysis of Ki67, Muc2, Villin, DLL1, DLL4, Notch1, Hes1, Bmi1, Lgr5, and CD44 in control or Torin-1-treated Tu12 (Xeno\#2 vs Xeno\#9, upper) or Tu22 (Xeno\#5 vs Xeno\#9, lower) tumors. Expression was normalized to GAPDH mRNA. Error bars represent upper and lower error limits based on replicate variability $\left({ }^{*} \mathrm{p}<0.05,{ }^{* *} p<0.01\right.$, *** $p<0.001$ ). (B) Images of PFA-fixed, paraffin-embedded serial sections of control or Torin-1-treated Tu22 tumors (Xeno\#5 vs Xeno\#7) stained with H\&E, mTOR Ser2481, Alcian Blue (A.B.), Muc2 (AEC, red color), cleaved caspase-3 (CC3) Asp175 (AEC, red color), Azan

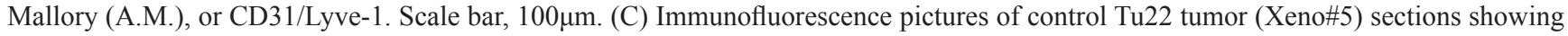
Podoplanin (Pdpln) expression in both lymphatic vessels $(l e f t)$ and tumor cells $(r i g h t)$ at the invasive front. Scale bars, 100 $\mu \mathrm{m}$. Podoplanin ${ }^{+}$ vessels were CD31- The human origin of Podoplanin ${ }^{+}$cells located outside vessels was confirmed by HLA staining. Podoplanin ${ }^{+}$cells exhibited round morphology and were CD44. (D) Bar graphs showing number of colonies generated from CD326 cells isolated from vehicle or Torin-1-treated xenografts. $10^{3}$ cells were plated on a 24-well plate previously coated with LA7 feeder layer cells, and grown for 1 week before scoring the number of colonies. 
marker Ki67, the Notch pathway members involved in angiogenesis DLL4 and Notch1 [30], and the CSC surface marker CD44 were significantly reduced in both Tu12 and Tu22 treated tumors. No changes in the mRNA levels of the goblet cell differentiation marker Muc2, the Notch effector Hes1, and the Polycomb member Bmil were observed. The enterocyte differentiation marker Villin, the Notch pathway component DLL1, and the crypt stem cell marker Lgr5 were decreased in Tu22, but not in Tu12 tumors, following treatment. Anti-CSC therapy is expected to promote differentiation; the reduction in Villin levels may therefore seem paradoxical. However, a previously unrecognized function of Villin in IEC survival was reported [31], indicating that Torin-1 might favor apoptosis by reducing Villin levels. A decrease in mTOR Ser2481, and an increase in CC3 and fibrotic tissue (Azan Mallory, A.M.) were observed in treated versus control tumors (Figure 7B). In accordance with molecular analysis, no changes in goblet cell numbers were found, as investigated by Muc2 and Alcian Blue (A.B.) stainings (Figure 7B). Importantly, treated tumors contained fewer blood vessels, as examined through CD31 staining (Figure 7B). Interestingly, Podoplanin expression characterized both lymphatic vessels and tumor cells at the invasive front of control tumors, while no positivity was observed in treated tumors (Figure 7C). Podoplanin ${ }^{+}$vessels were CD31- ${ }^{-}$Podoplanin ${ }^{+}$cells located outside vessels were human in origin, although HLA expression was dispersed throughout their cytoplasm. This is not surprising since tumor cells often down-regulate HLA antigens surface expression to escape immunological attack. Podoplanin ${ }^{+}$ cells exhibited round morphology typical of amoeboid motility and were CD44-. Loss of CD44 expression in invaded area is a good indicator of lymph-node metastasis in CRC [32]. Thus, while control tumors comprised cells with high metastatic potential, cells in treated tumors were less prone to migrate to distant sites.

Since in vitro cultured tumor cells might not maintain the exact properties of the primary tumor, by acquisition of additional gene alterations, we aimed at assessing Torin-1 effects on xenografts obtained from injection of freshly isolated metastatic CRC cells. After 5 months from injection, 6 out of 10 tumors had formed. Mice were therefore divided in two groups, and treated with $20 \mathrm{mg} / \mathrm{Kg}$ Torin-1 or vehicle every day up to 12 days (parental tumor was confirmed for mTOR pathway

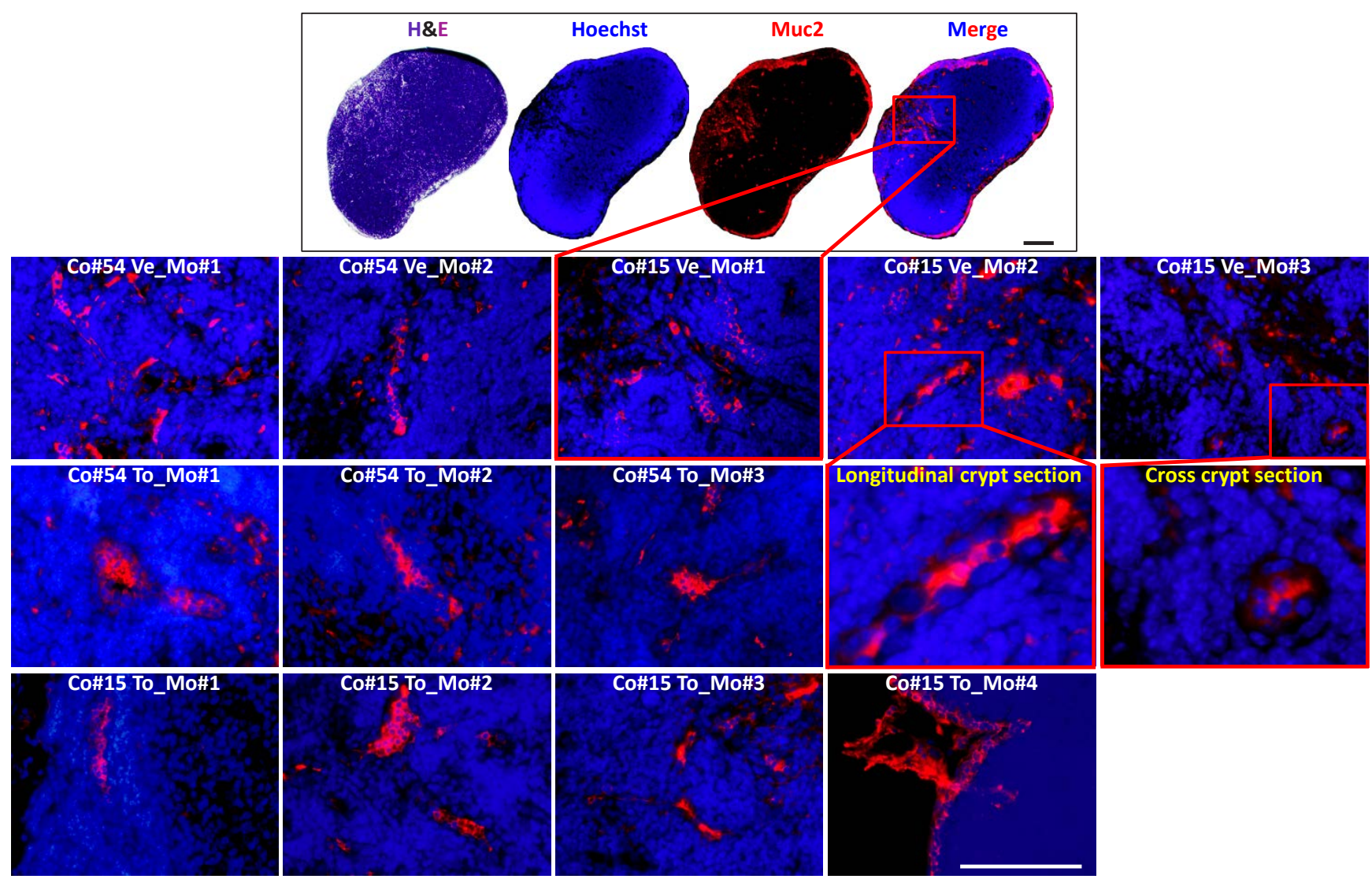

Figure 8: Torin-1 does not affect the survival of normal colon stem cells in vivo. (upper panel) H\&E or immunofluorescence staining of PFA-fixed, paraffin-embedded sections of a mouse lymph node showing engraftment of human fetal intestinal epithelial cells as revealed by Muc2 positivity. Scale bar, $100 \mu \mathrm{m}$. (lower panel) Representative Muc-2 reactive-colon crypts repopulating lymph nodes of mice (Mo) receiving injection of human fetal colon \#54 or 15 (Co\#54 and Co\#15, respectively), and subjected to vehicle or Torin-1

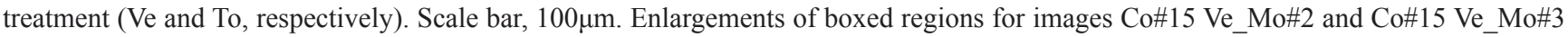
are shown. 
activation before beginning Torin-1 treatment, data not shown). Torin-1-treated tumors grew slower than control tumors (data not shown). Importantly, CD326 expression was reduced after treatment, as assessed by flow cytometry analysis on freshly isolated cells (data not shown). CD326 is one of the first and prominent immunotherapeutic targets in cancer therapy due to its frequent and high-level expression on most carcinomas of various origins. It can abrogate E-cadherin mediated cell-cell adhesion thereby promoting metastasis [33], and can support proliferation by enhancing Wnt signaling [34]. CD $326^{+}$cells from both groups were sorted and plated on stroma feeder layer. $\mathrm{CD} 26^{+}$cells isolated from vehicle-treated xenografts generated a higher number of colonies than $\mathrm{CD} 326^{+}$cells isolated from Torin-1-treated xenografts, and colonies were significantly bigger (Figure 7D). All these data support the potential of further development of Torin-1 as therapeutic for the treatment of CRC.

\section{Torin-1 does not affect the survival of normal colon stem cells in vivo.}

Because normal stem cells and CSCs share many traits, it seems reasonable to think that any therapy targeting CSCs may also destroy healthy tissues [35]. Given our recent finding that the mouse lymph node can be used as an in vivo organ factory to build up complex organ structures [36], we aimed at assessing the in vivo toxicity of Torin-1 against normal colon stem cells by recapitulating colon organ inside the mouse lymph node. To this purpose, we used human fetal intestinal epithelial cells, thought to be enriched in normal stem cells (Figure 8, upper panel). Following 3 weeks from cell transplantation, mice were treated with vehicle or $20 \mathrm{mg} /$ $\mathrm{Kg}$ Torin-1 once a day for 12 days. Tridimensional crypts could be observed in lymph nodes of both untreated and treated mice, to the same extent (Figure 8, lower panel). Thus, Torin-1 did not affect the survival of normal colon stem cells in vivo, suggesting its selectivity towards cancer cells.

\section{DISCUSSION}

Although during the last decades in vivo preclinical studies revealed the antitumor effect of several drugs against CRC, most patients experience a tumor recurrence. The main explanation for such a dismal prognosis is that common drugs leave behind CoCSCs, whose drug-induced positive selection renders tumors more aggressive. As cancer's Achilles' heel, CSCs have been intensively studied to develop more effective therapies. Because it plays such a crucial role in cancer biology, mTOR has emerged as a potential target for drug development. Several mTOR inhibitors, including Rapamycin, have already gone through clinical trials as single agents for treating various cancers without great success. Of the huge list of mTOR inhibitors developed, only Temsirolimus and Everolimus have been approved by the FDA for the treatment of advanced renal cell carcinoma [37]. Nevertheless, the role of mTOR inhibitors in cancer therapy continues to evolve, as new compounds are synthetized. Despite this, data comparing the effects of distinct mTOR inhibitors on CSCs are incomplete.

Here, we first analyzed metastatic CRC cells with the properties of intestinal stem cells as well as tumorinitiating cells for mTOR activation. We found mTOR complexes to be differently expressed in these cells, concluding that mTORC2 might be involved in the maintenance of the cancer stem-like phenotype, while mTORC1 might be involved in CoCSC maturation. This is in agreement with previous studies showing a role for mTORC1 in driving the differentiation of normal and cancer stem/progenitor cells [38-41].

CoCSCs expressed low levels of Akt Ser473, indicating that this kinase could not have been a major mTORC2 effector in our system. We indicated SGK1 as the possible main mTORC2 effector in CoCSCs, as highlighted by the negative effect on cancer properties following its knockdown. Akt hypophosphorylation and dependence of SGK family members for viability are known to occur most frequently in the context of wildtype Phosphatase and tensin homolog (PTEN), and helical PI3K alpha catalytic subunit kinase domain (PIK3CA) mutations [42]. Future studies will be conducted to confirm whether this genetic signature can predict resistance or sensitivity of CoCSCs to the different mTorKIs here studied. Unfortunately, the prognostic and predictive value of common mutations in patients with colon cancer is controversial, due to bias in research settings [43]. In our opinion, mTorKI resistance might also occur through less well-studied but equally important epigenetic mechanisms [44].

We therefore analyzed the effects of six mTOR inhibitors, including Torin-1, a highly potent and selective mTorKI [45]. Of the examined compounds, Torin-1 proved the most powerful inhibitor, suppressing CoCSC growth both in vitro and in vivo.

mTOR inhibitors can relieve negative feedbacks, resulting in strengthened oncogenic signals. This happened under Rapamycin exposure, which drove cells towards a pro-metastatic phenotype, confirming the notion that Rapamycin can have pro-tumor effects. Nevertheless, despite its role in activating oncogenetic pathways, Rapamycin has also been considered a tumor-preventive agent since it delays carcinogenesis in tumor-prone $\mathrm{p} 53^{+}$and $\mathrm{p} 53^{\%} /$ mice, most likely by slowing down the process of aging [46, 47]. mTOR inhibitors can have a doubleedged sword by activating autophagy, and autophagy itself has a double-edged sword in cancer by the promotion of metabolically stressed tumor cell survival. Indeed, pp242 protected CoCSCs from the effects of mTOR inhibition 
through autophagy activation, warranting considerable attention on newly developed inhibitors. The goal of any therapeutic strategy is to trigger CSC apoptosis, and Torin-1 successfully achieved this aim both in vitro and in vivo. It is possible that higher Torin-1 concentrations could increase antitumor response in vivo. However, 20mg/ $\mathrm{Kg}$ Torin-1 was sufficient to hinder CoCSC expansion, angio-/lympho-genesis, and invasion in vivo. Importantly, Torin-1-resistant CoCSCs exhibited much reduced tumorigenicity or were even non-tumorigenic. Moreover, Torin-1 did not affect the survival of normal colon stem/ progenitor cells in vivo, thus encouraging its potential use for metastatic CRC therapy. Recently, Torin-2, which has better pharmacokinetic properties and an improved synthetic route than Torin-1 has been synthetized [48]. Although to our knowledge no studies have been reported so far to elucidate its effectiveness in cancer, we do not exclude it could also be used to successfully treat CRC. Inappropriate activation of PI3K signaling is one of the most common features of CRC. Several studies have shown that inhibition at multiple levels of the PI3K pathway results in FOXO-dependent feedback reactivation of several receptor tyrosine kinases (RTKs), which, in turn, limit the sustained inhibition of this pathway [49]. This suggests that if used as single agents, PI3K pathway inhibitors may have limited clinical activity. Conversely, dual inhibition of PI3K and mTORC1/2 signaling induced tumor regression in several in vivo human tumor xenograft models, and might show greater efficacy than mTorKIs at depleting CoCSCs [50].

\section{METHODS}

Cells.

CoCSCs were cultured as previously described [23].

\section{Reagents, plastics, and instruments:}

Antibodies used are indicated in Supplementary Table 1. CopGFP control (sc-108084), control shRNA (sc-108080), and SGK1 shRNA (sc-38913-V) lentiviral particles, and SGK1 primers (sc-38913-PR) were purchased from Santa Cruz. Sequences of other primers used are indicated in Supplementary Table 2. Drugs were purchased as follows: Rapamycin (R-5000) from LC Laboratories; WYE-354 (CD0270), pp242 (CD0258), and $\mathrm{Ku}-0063794$ (CD0274) from Chemdea; Temsirolimus (PZ0020), 5-Fluorouracil (F6627), and Oxaliplatin (O9512) from Sigma; Torin-1 (1222998-36-8) from Tocris Biosciences. All drugs except Oxaliplatin were dissolved in DMSO as stock solutions, and then diluted with culture medium. Oxaliplatin was dissolved in deionized water. Kits were purchased as follows: RNeasy Mini Kit (74104) from Qiagen; iScript ${ }^{\mathrm{TM}}$ Reverse Transcription Supermix for RT-qPCR (170-8841), iTaq DNA Polymerase kit (1708870 ), and SsoAdvanced ${ }^{\mathrm{TM}}$ SYBR ${ }^{\circledR}$ Green supermix (172-5261) from Bio-Rad; CellTiter 96® AQueous Assay (G3580), DeadEnd ${ }^{\mathrm{TM}}$ Colorimetric TUNEL System (G7360), and Caspase-Glo® 3/7 Assay (G8091) from Promega. Transwells (07-200-150) were purchased from Corning. Ibidi culture inserts (80209) were used for migration assay. Flow analysis was performed on a Miltenyi MACSQuant Analyzer. Sorting was performed on a BectonDickenson FACSAria II SORP cell sorter. Final data analysis was done using FlowJo software (TreeStar). A C1000 thermal cycler (Biorad) and a StepOnePlus ${ }^{\mathrm{TM}}$ Real-Time PCR System (Applied Biosystems) were used for gene amplification.

\section{Colon cancer xenografts and treatment.}

Tumor tissues were minced into small fragments with scalpels and then digested using a two-step collagenase method. Freshly isolated cells from primary tumors or CoCSCs $\left(5 \times 10^{5}\right)$ were suspended in HBSS:Matrigel $(1: 1)$ and injected s.c. into both flanks of 5-week-old BALB/c nude mice (Charles River, $n=5$ per group). $20 \mathrm{mg} / \mathrm{Kg}$ Torin-1, as a suspension in $20 \%$ N-methyl-2-pyrrolidone/40\% PEG400/40\% water [45], or vehicle was delivered by i.p. injection once daily for 12 days after the tumor was established. Tumors were measured every day using a caliper and tumor volumes calculated according to the formula $\mathrm{V}=\pi / 6 \times($ larger diameter $) \times(\text { smaller diameter })^{2}$. At the end of the treatment mice were killed by $\mathrm{CO}_{2}$ euthanasia. Xenografted tumors were excised, weighed, photographed, fixed in buffered formalin, and embedded in paraffin for histological and immunohistochemical examination, or stored in RNA later (Qiagen) prior to RNA isolation, or subjected to flowcytometric analysis.

\section{Fetal intestinal epithelial cell transplantation and treatment.}

Normal colon was obtained from 2 fetuses (\#15 and \#54, 21 and 23 weeks, respectively) from elective abortions performed at Magee Women's Hospital, Pittsburgh, PA. The colon was cut longitudinally in HBSS, contents rinsed, cut into 1 -inch pieces, transferred to EBSS/10mM EGTA/1\% HEPES (Life Technologies/ Sigma-Aldrich/Mediatech) and minced. Tissue was then transferred to a tube and incubated for $5 \mathrm{~min}$ at room temperature. After an EBSS wash, the tissue was treated three times with a cocktail containing $1 \mathrm{mg} / \mathrm{mL}$ collagenase II (Life Technologies), 1mg/mL hyaluronidase (SigmaAldrich), and $20 \mu \mathrm{g} / \mathrm{mL}$ DNase I (Roche) in HBSS $/ 1 \%$ HEPES for $20 \mathrm{~min}$. Tissue/cell suspensions were passed through a $100 \mathrm{~m}$ cell strainer to isolate single cells from 
undigested tissue.

For lymph node transplantation, recipient mice (BALB/c nude, $n=12$ ) were anesthetized with $1-3 \%$ isoflurane. A small incision was made in the abdomen to expose jejunal lymph nodes. A $25 \mu \mathrm{L}$ gas-tight removable needle syringe (Hamilton, 7656-01) with a removable needle (gauge 27) (Hamilton, 7803-01) was used to slowly inject the cell suspension $\left(2 \times 10^{5}\right.$ cells/mouse) into a single lymph node. Light cauterization was used to seal the opening. The wound was then closed with surgical sutures. Ketoprofen ( $2 \mathrm{mg} / \mathrm{kg}$, IM) treatment for postoperative pain relief was initiated right after surgery and continued for 2 additional consecutive days. Three weeks later, mice were divided in two groups; one group received i.p. injection of $20 \mathrm{mg} / \mathrm{Kg}$ Torin-1 once a day for 12 days $(n=7)$; the other group received vehicle $(n=5)$. At the end of Torin- 1 treatment, all mice were euthanized, their lymph nodes were collected, fixed 2 hours in $4 \%$ PFA, and embedded in paraffin for analysis. Sections were stained with H\&E or Muc2 antibody (antibody used is indicated in Supplementary Table 1).

\section{Statistical Analysis.}

Data are presented as means \pm SD. Statistical analysis was performed using Student's t test $(\mathrm{p}<0.05$ was considered significant).

\section{ACKNOWLEDGEMENTS}

This work was supported by Ri.MED foundation (MGF). The authors thank Lynda Guzik for help with cell cycle analysis and cell sorting, and for English editing, and Julie Chandler for providing qRT-PCR primers and human fetal intestinal epithelial cells.

\section{REFERENCES}

1. Jemal A, Siegel R, Xu J and Ward E. Cancer statistics, 2010. CA: a cancer journal for clinicians. 2010; 60(5):277300.

2. Foster KG and Fingar DC. Mammalian target of rapamycin (mTOR): conducting the cellular signaling symphony. The Journal of biological chemistry. 2010; 285(19):1407114077.

3. Sarbassov DD, Ali SM, Kim DH, Guertin DA, Latek RR, Erdjument-Bromage H, Tempst P and Sabatini DM. Rictor, a novel binding partner of $\mathrm{mTOR}$, defines a rapamycininsensitive and raptor-independent pathway that regulates the cytoskeleton. Current biology : CB. 2004; 14(14):12961302 .

4. Sarbassov DD, Ali SM, Sengupta S, Sheen JH, Hsu PP, Bagley AF, Markhard AL and Sabatini DM. Prolonged rapamycin treatment inhibits mTORC2 assembly and Akt/ PKB. Molecular cell. 2006; 22(2):159-168.
5. Fingar DC, Salama S, Tsou C, Harlow E and Blenis J. Mammalian cell size is controlled by mTOR and its downstream targets S6K1 and 4EBP1/eIF4E. Genes \& development. 2002; 16(12):1472-1487.

6. Julien LA, Carriere A, Moreau J and Roux PP. mTORC1activated S6K1 phosphorylates Rictor on threonine 1135 and regulates mTORC2 signaling. Molecular and cellular biology. 2010; 30(4):908-921.

7. Carlson CJ, White MF and Rondinone CM. Mammalian target of rapamycin regulates IRS-1 serine 307 phosphorylation. Biochemical and biophysical research communications. 2004; 316(2):533-539.

8. Yu Y, Yoon SO, Poulogiannis G, Yang Q, Ma XM, Villen J, Kubica N, Hoffman GR, Cantley LC, Gygi SP and Blenis J. Phosphoproteomic analysis identifies Grb10 as an mTORC1 substrate that negatively regulates insulin signaling. Science. 2011; 332(6035):1322-1326.

9. Sarbassov DD, Guertin DA, Ali SM and Sabatini DM. Phosphorylation and regulation of Akt/PKB by the rictormTOR complex. Science. 2005; 307(5712):1098-1101.

10. Jacinto E, Loewith R, Schmidt A, Lin S, Ruegg MA, Hall A and Hall MN. Mammalian TOR complex 2 controls the actin cytoskeleton and is rapamycin insensitive. Nature cell biology. 2004; 6(11):1122-1128.

11. Garcia-Martinez JM and Alessi DR. mTOR complex 2 (mTORC2) controls hydrophobic motif phosphorylation and activation of serum- and glucocorticoid-induced protein kinase 1 (SGK1). The Biochemical journal. 2008; 416(3):375-385.

12. Zhou H, Luo Y and Huang S. Updates of mTOR inhibitors. Anti-cancer agents in medicinal chemistry. 2010; 10(7):571581.

13. Aoki K, Tamai Y, Horiike S, Oshima M and Taketo MM. Colonic polyposis caused by mTOR-mediated chromosomal instability in Apc+/Delta716 Cdx2+/- compound mutant mice. Nature genetics. 2003; 35(4):323-330.

14. Fujishita T, Aoki K, Lane HA, Aoki M and Taketo MM. Inhibition of the mTORC1 pathway suppresses intestinal polyp formation and reduces mortality in ApcDelta716 mice. Proceedings of the National Academy of Sciences of the United States of America. 2008; 105(36):13544-13549.

15. Shao J, Evers BM and Sheng H. Roles of phosphatidylinositol 3'-kinase and mammalian target of rapamycin/p70 ribosomal protein S6 kinase in K-Rasmediated transformation of intestinal epithelial cells. Cancer research. 2004; 64(1):229-235.

16. Gulhati P, Cai Q, Li J, Liu J, Rychahou PG, Qiu S, Lee EY, Silva SR, Bowen KA, Gao T and Evers BM. Targeted inhibition of mammalian target of rapamycin signaling inhibits tumorigenesis of colorectal cancer. Clinical cancer research : an official journal of the American Association for Cancer Research. 2009; 15(23):7207-7216.

17. Roper J, Richardson MP, Wang WV, Richard LG, Chen W, Coffee EM, Sinnamon MJ, Lee L, Chen PC, Bronson RT, 
Martin ES and Hung KE. The dual PI3K/mTOR inhibitor NVP-BEZ235 induces tumor regression in a genetically engineered mouse model of PIK3CA wild-type colorectal cancer. PloS one. 2011; 6(9):e25132.

18. Blaser B, Waselle L, Dormond-Meuwly A, Dufour M, Roulin D, Demartines N and Dormond O. Antitumor activities of ATP-competitive inhibitors of mTOR in colon cancer cells. BMC cancer. 2012; 12:86.

19. Zhang $\mathrm{Y}$ and Zheng XF. mTOR-independent 4E-BP1 phosphorylation is associated with cancer resistance to mTOR kinase inhibitors. Cell Cycle. 2012; 11(3):594-603.

20. O'Brien CA, Pollett A, Gallinger S and Dick JE. A human colon cancer cell capable of initiating tumour growth in immunodeficient mice. Nature. 2007; 445(7123):106-110.

21. Ricci-Vitiani L, Lombardi DG, Pilozzi E, Biffoni M, Todaro M, Peschle C and De Maria R. Identification and expansion of human colon-cancer-initiating cells. Nature. 2007; 445(7123):111-115.

22. Cai Z, Ke J, He X, Yuan R, Chen Y, Wu X, Wang L, Wang J, Lan P and $\mathrm{Wu} X$. Significance of mTOR Signaling and Its Inhibitor Against Cancer Stem-Like Cells in Colorectal Cancer. Annals of surgical oncology. 2013.

23. Odoux C, Fohrer H, Hoppo T, Guzik L, Stolz DB, Lewis DW, Gollin SM, Gamblin TC, Geller DA and Lagasse E. A stochastic model for cancer stem cell origin in metastatic colon cancer. Cancer research. 2008; 68(17):6932-6941.

24. Zhang YJ, Dai Q, Sun DF, Xiong H, Tian XQ, Gao FH, $\mathrm{Xu} \mathrm{MH}$, Chen GQ, Han ZG and Fang JY. mTOR signaling pathway is a target for the treatment of colorectal cancer. Annals of surgical oncology. 2009; 16(9):2617-2628.

25. Baba Y, Nosho K, Shima K, Hayashi M, Meyerhardt JA, Chan AT, Giovannucci E, Fuchs CS and Ogino S. Phosphorylated AKT expression is associated with PIK3CA mutation, low stage, and favorable outcome in 717 colorectal cancers. Cancer. 2011; 117(7):1399-1408.

26. Cybulski N and Hall MN. TOR complex 2: a signaling pathway of its own. Trends in biochemical sciences. 2009; 34(12):620-627.

27. Shmelkov SV, Butler JM, Hooper AT, Hormigo A, Kushner J, Milde T, St Clair R, Baljevic M, White I, Jin DK, Chadburn A, Murphy AJ, Valenzuela DM, Gale NW, Thurston G, Yancopoulos GD, et al. CD133 expression is not restricted to stem cells, and both CD133+ and CD133metastatic colon cancer cells initiate tumors. The Journal of clinical investigation. 2008; 118(6):2111-2120.

28. Dalerba P, Dylla SJ, Park IK, Liu R, Wang X, Cho RW, Hoey T, Gurney A, Huang EH, Simeone DM, Shelton AA, Parmiani G, Castelli C and Clarke MF. Phenotypic characterization of human colorectal cancer stem cells. Proceedings of the National Academy of Sciences of the United States of America. 2007; 104(24):10158-10163.

29. Visvader JE and Lindeman GJ. Mammary stem cells and mammopoiesis. Cancer research. 2006; 66(20):9798-9801.

30. Yan M. Therapeutic promise and challenges of targeting
DLL4/NOTCH1. Vascular cell. 2011; 3:17.

31. Wang Y, Srinivasan K, Siddiqui MR, George SP, Tomar A and Khurana S. A novel role for villin in intestinal epithelial cell survival and homeostasis. The Journal of biological chemistry. 2008; 283(14):9454-9464.

32. Asao T, Nakamura J, Shitara Y, Tsutsumi S, Mochiki E, Shimura T, Takenoshita S and Kuwano H. Loss of standard type of CD44 expression in invaded area as a good indicator of lymph-node metastasis in colorectal carcinoma. Diseases of the colon and rectum. 2000; 43(9):1250-1254; discussion 1254-1255.

33. Winter MJ, Nagelkerken B, Mertens AE, Rees-Bakker HA, Briaire-de Bruijn IH and Litvinov SV. Expression of Ep-CAM shifts the state of cadherin-mediated adhesions from strong to weak. Experimental cell research. 2003; 285(1):50-58.

34. Maetzel D, Denzel S, Mack B, Canis M, Went P, Benk M, Kieu C, Papior P, Baeuerle PA, Munz M and Gires O. Nuclear signalling by tumour-associated antigen EpCAM. Nature cell biology. 2009; 11(2):162-171.

35. Francipane MG, Chandler J and Lagasse E. Cancer Stem Cells: A Moving Target. Current pathobiology reports. 2013; 1(2):111-118.

36. Komori J, Boone L, DeWard A, Hoppo T and Lagasse E. The mouse lymph node as an ectopic transplantation site for multiple tissues. Nature biotechnology. 2012; 30(10):976983.

37. Battelli $\mathrm{C}$ and Cho DC. mTOR inhibitors in renal cell carcinoma. Therapy. 2011; 8(4):359-367.

38. Castilho RM, Squarize CH, Chodosh LA, Williams BO and Gutkind JS. mTOR mediates Wnt-induced epidermal stem cell exhaustion and aging. Cell stem cell. 2009; 5(3):279289.

39. Easley CAt, Ben-Yehudah A, Redinger CJ, Oliver SL, Varum ST, Eisinger VM, Carlisle DL, Donovan PJ and Schatten GP. mTOR-mediated activation of p70 S6K induces differentiation of pluripotent human embryonic stem cells. Cellular reprogramming. 2010; 12(3):263-273.

40. Tyler WA, Gangoli N, Gokina P, Kim HA, Covey M, Levison SW and Wood TL. Activation of the mammalian target of rapamycin (mTOR) is essential for oligodendrocyte differentiation. The Journal of neuroscience : the official journal of the Society for Neuroscience. 2009; 29(19):63676378.

41. Yang Z, Zhang L, Ma A, Liu L, Li J, Gu J and Liu Y. Transient mTOR inhibition facilitates continuous growth of liver tumors by modulating the maintenance of CD133+ cell populations. PloS one. 2011; 6(12):e28405.

42. Vasudevan KM, Barbie DA, Davies MA, Rabinovsky R, McNear CJ, Kim JJ, Hennessy BT, Tseng H, Pochanard P, Kim SY, Dunn IF, Schinzel AC, Sandy P, Hoersch S, Sheng Q, Gupta PB, et al. AKT-independent signaling downstream of oncogenic PIK3CA mutations in human cancer. Cancer cell. 2009; 16(1):21-32. 
43. Day FL, Jorissen RN, Lipton L, Mouradov D, Sakthianandeswaren A, Christie M, Li S, Tsui C, Tie J, Desai J, Xu ZZ, Molloy P, Whitehall V, Leggett BA, Jones IT, McLaughlin S, et al. PIK3CA and PTEN gene and exon mutation-specific clinicopathologic and molecular associations in colorectal cancer. Clinical cancer research : an official journal of the American Association for Cancer Research. 2013; 19(12):3285-3296.

44. Francipane MG and Lagasse E. Genetic Instability and Epigenetic Diversity of Cancer: A Focus On Colorectal Cancer. In: "Cancer Targeted Drug Delivery: Elusive Dream" (YH Bae et al, eds) Springer 2013.

45. Liu Q, Chang JW, Wang J, Kang SA, Thoreen CC, Markhard A, Hur W, Zhang J, Sim T, Sabatini DM and Gray NS. Discovery of 1-(4-(4-propionylpiperazin-1-yl)3-(trifluoromethyl)phenyl)-9-(quinolin-3-yl)benz $\quad \mathrm{o}[\mathrm{h}]$ $[1,6]$ naphthyridin-2(1H)-one as a highly potent, selective mammalian target of rapamycin (mTOR) inhibitor for the treatment of cancer. Journal of medicinal chemistry. 2010; 53(19):7146-7155.

46. Comas M, Toshkov I, Kuropatwinski KK, Chernova OB, Polinsky A, Blagosklonny MV, Gudkov AV and Antoch MP. New nanoformulation of rapamycin Rapatar extends lifespan in homozygous p53-/- mice by delaying carcinogenesis. Aging. 2012; 4(10):715-722.

47. Komarova EA, Antoch MP, Novototskaya LR, Chernova OB, Paszkiewicz G, Leontieva OV, Blagosklonny MV and Gudkov AV. Rapamycin extends lifespan and delays tumorigenesis in heterozygous p53+/- mice. Aging. 2012; 4(10):709-714.

48. Liu Q, Wang J, Kang SA, Thoreen CC, Hur W, Ahmed T, Sabatini DM and Gray NS. Discovery of 9-(6-aminopyridin3-yl)-1-(3-(trifluoromethyl)phenyl)benzo[h][1,6]

naphthyridin-2(1H)-one (Torin2) as a potent, selective, and orally available mammalian target of rapamycin (mTOR) inhibitor for treatment of cancer. Journal of medicinal chemistry. 2011; 54(5):1473-1480.

49. Garrett JT, Chakrabarty A and Arteaga CL. Will PI3K pathway inhibitors be effective as single agents in patients with cancer? Oncotarget. 2011; 2(12):1314-1321.

50. Martelli AM, Chiarini F, Evangelisti C, Cappellini A, Buontempo F, Bressanin D, Fini M and McCubrey JA. Two hits are better than one: targeting both phosphatidylinositol 3-kinase and mammalian target of rapamycin as a therapeutic strategy for acute leukemia treatment. Oncotarget. 2012; 3(4):371-394. 